\title{
EFEITOS DE SENTIDO DO DISCURSO ORGANIZACIONAL EM COMBATE AO VÍRUS HIV
}

\author{
PAULO EDUARDO DÓRO PRESTES \\ UNIVERSIDADE FEDERAL DE SANTA MARIA \\ FREDERICO WESTPHALEN, RIO GRANDO DO SUL, BRASIL \\ EDUARD2298@GMAIL.COM \\ MARLUZA DA ROSA \\ UNIVERSIDADE FEDERAL DE SANTA MARIA \\ FREDERICO WESTPHALEN, RIO GRANDO DO SUL, BRASIL \\ MARLUZA.ROSA@GMAIL.COM
}




\section{EFEITOS DE SENTIDO DO DISCURSO ORGANIZACIONAL EM COMBA- TE AO VÍRUS HIV}

Resumo: Sob a ótica das Relações Públicas, esta pesquisa se desenvolve a partir dos fundamentos teóricos de Pêcheux (1990), Orlandi (2007) e Fernandes (2008) sobre a teoria do discurso, com o objetivo de identificar quais efeitos de sentido se produzem a partir do discurso materializado no cartaz de uma empresa, localizada em Santa Cruz do Sul (RS), em combate ao vírus HIV.

Palavras-chave: Análise do discurso; Discurso organizacional; Vírus HIV.

\section{EFECTOS DE SENTIDO DEL DISCURSO ORGANIZACIONAL EN LA LU- CHA CONTRA EL VÍRUS VIH}

Resúmen: En la óptica de las relaciones públicas, esta investigación se desarrolla a partir de los fundamentos teóricos de Pêcheux (1990), Orlandi (2007) y Fernandes (2008) sobre la teoría del discurso, con el objetivo de identificar cuales efectos de sentido se producen a partir del discurso materializado en el cartel de una empresa, ubicada en Santa Cruz do Sul (RS), en la lucha conta el virus VIH.

Palabras clave: Análisis del discurso; Discurso organizacional; Virus VIH.

\section{EFFECTS OF SENSE FROM ORGANIZATIONAL DISCOURSE REGAR- DING HIV VIRUS}

Abstract: From Public Relations's perspective, this research is based on theoretical foundations from Pêcheux (1990), Orlandi (2007) and Fernandes (2008) about discourse analysis, with the purpose of identifying which effects of sense are produced from the discourse materialized in an awareness poster about HIVvirus of a company located in Santa Cruz do Sul (RS). Keywords: Discourse analysis; Organizational discourse; HIV virus. 


\section{INTRODUÇÃO}

O êxodo rural ocasionou a aglomeração de pessoas nas cidades, sua estruturação em classes, bem como definiu as funções dos sujeitos na esfera social. Além disso, a urbanização provocou a disseminação de conhecimentos, hábitos e, também, de doenças. Nesse contexto, as organizações passaram a possuir papel de relevância no âmbito social, pois, além de fornecerem serviços e produtos para o consumo. Posicionam-se e conscientizam sobre temas variados, uma vez que se relacionam com diversos públicos e necessitam deles para a continuidade da produção.

A comunicação interna, por exemplo, um dos objetos de pesquisa das Relações Públicas (KUNSCH, 2003), é realizada na ambiência organizacional para um dos públicos das empresas, os colaboradores, a fim de fornecer informações que a gestão e os profissionais de comunicação consideram relevantes e, assim, gerar bons relacionamentos entre gestores e equipes. Nesse cenário, há possibilidade de utilizarmos diversos instrumentos de comunicação dirigida para que os conteúdos cheguem até esse público e o objetivo das ações seja atingido. Porém, com o avanço tecnológico da sociedade, não há como segmentar a comunicação apenas para o espaço interno, visto que os dispositivos móveis possibilitam a disseminação das informações a outros públicos.

Este trabalho analisa um texto de campanha de comunicação interna de uma empresa produtora de embalagens e etiquetas, localizada na cidade de Santa Cruz do Sul, interior do Rio Grande do Sul. A organização ganhou espaço na mídia em maio de 2015, quando produziu um cartaz, supostamente de conscientização e combate ao vírus HIV', direcionado aos seus mais de 700 colaboradores. Após o compartilhamento da imagem na rede social Facebook, iniciou-se uma repercussão midiática, assim como discussões sobre os possíveis efeitos de sentido acerca do texto, que aborda o ato sexual e a sua relação com o referido vírus.

A circulação do discurso organizacional, como no caso da instituição

1 O vírus da imunodeficiência humana (HIV) é o causador da doença Aids, que ataca o sistema imunológico e impede que o organismo se defenda de outras doenças, segundo o Departamento de IST, Aids e Hepatites Virais. As pessoas podem ser infectadas em relações sexuais, transfusões de sangue, transmissão vertical (da mãe para o filho, durante a gestação), entre outras maneiras. A epidemia iniciou-se em 1980 no Brasil e o estado do Rio Grande do Sul é o estado com maior índice de Aids por estado, segundo o Ministério da Saúde (2011). 
em questão, possibilita investigações sobre as condições de produção dos dizeres, seus sentidos possíveis e o posicionamento da organização. De acordo com informações encontradas no site institucional, a organização respeita as diferenças, é ética em todos os seus relacionamentos, valoriza todas as formas de vida e atua em razão das pessoas, ajudando-as a alcançarem seu bem-estar. Porém, o texto do cartaz em discussão pode não respeitar todas essas condições ou mesmo ir contra os valores que empresa afirma defender, visto que pode produzir sentidos diversos que, não só não contribuem para a conscientização sobre as formas de transmissão do vírus, como também desrespeitam os soropositivos.

Inserido no campo das Relações Públicas, o artigo se desenvolve com base nos fundamentos teóricos da Análise do Discurso, a partir dos estudos de Pêcheux (1990), Orlandi (2007) e Fernandes (2008). O objetivo é identificar quais efeitos de sentido se produzem a partir do discurso materializado no instrumento de comunicação interna. Para o desenvolvimento da pesquisa, realizamos uma revisão bibliográfica, a fim de compreender os fundamentos teóricos sobre discurso e, também, recorremos à Análise do Discurso, constituída pelo referencial teórico de linha francesa, para analisarmos o texto.

\section{FUNDAMENTOS TEÓRICOS SOBRE DISCURSO}

No que concerne ao termo discurso, não existe um consenso no meio acadêmico (BRASIL, 2011). No senso comum, a palavra remete às práticas de falas de personalidades da mídia, políticos ou gestores de organizações reconhecidas. Porém, para entrarmos no campo científico que considera o discurso como um objeto de pesquisa, é preciso fundamentá-lo como um conceito. Por essa razão, tratamos, neste trabalho, de uma teoria do discurso, mais precisamente de orientação francesa.

Para Fernandes (2008), em seu percurso introdutório à Análise de Discurso, o discurso não é visto como um texto, uma fala ou uma língua, mas precisa desses elementos linguísticos para ser materializado. Nesse aspecto, o autor afirma que o discurso não é só constituído por mecanismos linguísticos, mas também pelos aspectos históricos e socioideológicos que estão relacionados a ele, aqui chamados de condições de produção, que colocarão os interlocutores em determinados lugares discursivos.

Essa importância de compreender o que existe além dos elementos linguísticos é postulada por Pêcheux (1990, p. 79), um dos fundadores dos 
estudos do discurso, quando argumenta que não é possível "analisar um discurso como um texto, isto é, como uma sequência linguística fechada sobre si mesma, mas que é necessário referi-lo ao conjunto de discursos possíveis a partir de um estado definido das condições de produção". Assim, faz-se necessário compreender que todo discurso é atravessado por outros;

o contexto histórico e os lugares socioideológicos dos produtores dos discursos também devem ser considerados para a formulação de toda e qualquer análise.

Nessa perspectiva, Orlandi (1994, p. 56) explica que "no discurso, o mundo é apreendido, trabalhado pela linguagem e cabe ao analista procurar apreender a construção discursiva dos referentes". Nota-se, a partir dessa afirmação, que a relação dos sujeitos com o mundo é propagada nos discursos,e os analistas devem compreender os efeitos que podem decorrer da produção e da circulação destes, relacionadas a diferentes tipos de contexto: o contexto imediato e o contexto amplo, os quais se referem às condições de produção dos discursos.

O contexto imediato está relacionado ao ato de produzir o discurso em si, enquanto o contexto amplo envolve as questões históricas, sociais e ideológicas dos sujeitos que produzem o discurso. Consequentemente, mostra-se pertinente o trabalho com a noção de interdiscurso, já que ele é o que fala antes, o que está implicitamente associado aos discursos e o que está na constituição do dizer, ligado à memória discursiva. "O interdiscurso é todo o conjunto de formulações feitas e já esquecidas que determinam o que dizemos" (ORLANDI, 2007, p. 33).

O interdiscurso, então, está relacionado à história e ao lugar de onde falam os sujeitos. Ele determina o que vai estar presente no dizer, pois está relacionado à memória discursiva, ou seja, está em outros dizeres, que foram historicamente construídos pela sociedade e que determinam a produção de novos discursos e, consequentemente, dos efeitos de sentido que a partir deles se constituirão.

Os discursos produzirão sentidos diferentes de acordo com a formação discursiva em que são tomados pelos interlocutores. Visto que cada sujeito ocupa um lugar determinado em uma rede de formações discursivas, os sentidos decorrentes das palavras serão distintos, o que implica considerar que estas não possuem um sentido fixo e permanente, pelo contrário, ele se modifica de acordo com o momento histórico e social, produzindo efeitos 
distintos nos sujeitos (FERNANDES, 2008).

Para produzir sentidos, as ideologias constituem os processos discursivos juntamente com a linguagem. Todavia, os conteúdos das ideologias não são de interesse para os estudos de Análise do Discurso, apenas os processos que se integram com a linguagem e os outros fatores, já mencionados, para, então, produzir discursos. "A ideologia não é " $x$ ", mas o mecanismo de produzir "x"”, como argumenta Orlandi (1994, p. 56).

Como já referido, o âmbito social também está envolvido nos discursos. Não se trata, contudo, da posição social em que os indivíduos estão colocados, ou seja, de classe, gênero ou profissão, mas sim da formação imaginária que se constrói a partir das relações sociais desses sujeitos que, então, inserem-se em determinadas posições discursivas (ORLANDI, 1994).

Um exemplo disso é quando uma pessoa negra, brasileira, de baixa renda e com falta de acesso à educação e aos serviços básicos dos cidadãos, posiciona-se, discursivamente, contra as políticas de ações afirmativas desenvolvidas pelo Estado para sanar as necessidades do grupo social ao qual pertence, que, por determinações históricas, encontra-se compartilha de sua condição. $O$ exemplo permite afirmar que o lugar social não define a posição discursiva dos sujeitos, ou seja, o dizer não é produzido a partir do lugar biopsicossocialindividual, mas a partir de uma posição-sujeito discursiva, inscrita nas formações imaginárias que a constroem. A posição-sujeito sustentada no exemplo dado, marcadamente, não condiz com a situação em que está o indivíduo biopsicossocial.

Orlandi (2007, p. 40) argumenta que as formações imaginárias são construídas por meio de mecanismos que produzem "imagens dos sujeitos e dos objetos do discurso, dentro de uma conjuntura sócio-histórica". Além disso, a autora define as formações imaginárias como um jogo que comanda a troca de palavras e que está relacionado a outros dizeres e ao contexto social, histórico e ideológico dos sujeitos; isso quer dizer que todo discurso será pensado a partir da imagem que os sujeitos possuem de suas posições discursivas, não de seus lugares sociais. Assim, a formulação do discurso se constituirá a partir de uma noção imaginária de quem são os sujeitos interlocutores no processo discursivo: interlocutor A (quem sou eu para lhe falar assim?) e interlocutor B (quem é ele para que eu lhe fale assim?).

As formações imaginárias estão atreladas a relações de força, segundo Orlandi (2007), e essas relações sustentam as hierarquias construídas no âmbito social. A fala de um chefe vale mais do que a fala de um funcionário, 
por exemplo, e isso se deve às imagens que se tem da posição de chefe. Nesse sentido, entendemos que, na análise desenvolvida a seguir, o texto do cartaz da empresa em questão pede para que não se faça sexo com os moradores da cidade de Santa Cruz do Sul, o que supostamente se justificaria por haver um alto índice de pessoas contaminadas pelo vírus HIV na cidade (ou seja, o enunciado já se ancora em uma imagem que se constrói acerca dessas pessoas). A formulação do cartaz e sua circulação interna se atribuem a sujeitos que estão em uma posição discursiva mais reconhecida na escala de hierarquia da organização, o que, de certo modo, cercearia seus sentidos, sugerindo a materialização de um discurso de responsabilidade social. O texto, porém, teve repercussão midiática e, em consequência, foi interpretado por outros públicos, a partir de condições de produção e circulação outras, que excedem o ambiente interno e que produzem, como efeito do mesmo enunciado, a materialização de um discurso de preconceito e exclusão.

\section{ANÁlise do CARTAZ EM COMBATE AO víRUS HIV}

Sob a ótica das Relações Públicas, a comunicação interna é desenvolvida para atingir um dos diversos públicos que se relacionam com as organizações. Nesse contexto, pretende-se informar/dar visibilidade a notícias ou causas de interesse das organizações a seus colaboradores por meio de produtos de comunicação audiovisuais, impressos, digitais ou radiofônicos.

A empresa em questão, fornecedora de produtos de borracha e localizada na cidade de Santa Cruz do Sul (RS), produziu um cartaz para ser exibido aos seus funcionários no espaço interno, a fim de conscientizá-los em relação ao vírus HIV. Porém, como a sociedade encontra-se em uma ambiência midiatizada, onde não há mais controle do que pode ser difundido na rede de Internet, o produto comunicacional que era direcionado a um público segmentado foi veiculado na mídia social Facebook por um dos seus colaboradores. $O$ texto ganhou repercussão midiática e atingiu diversos públicos da organização, prejudicando a sua imagem organizacional, visto que se passou a questionar esse posicionamento no cartaz e a criticar o modo como foi elaborado.

Analisa-se, portanto, o discurso materializado no cartaz institucional a partir dos fundamentos teóricos sobre discurso advindos da Análise do Discurso. $O$ instrumento de comunicação dirigida, de cor vermelha, com as pa- 
lavras destacadas em branco, necessita, primeiramente, ser observado por meio de uma imagem que o representa. Assim, poderemos realizar a análise proposta:

Figura 1: Instrumento de comunicação interna de uma organização destinado à conscientizaçãodos colaboradores.

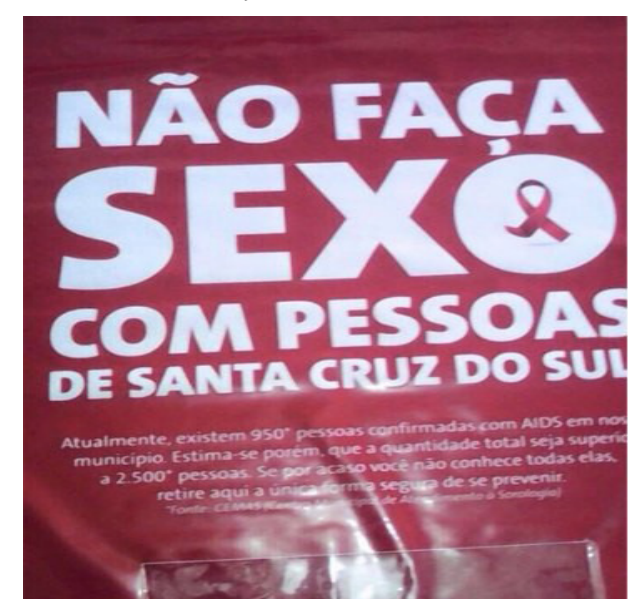

Fonte: Disponível em <http://www.correiodopovo.com.br/Noticias/555876/Cartaz-deempresa-sobre-Aids-causa-polemica->. Acesso em: 08 nov. 2017.

Após a observação da imagem, precisamos entender as condições de produção do discurso, ou seja, o contexto imediato, sócio-histórico e ideológico que, segundo Orlandi (2007), permeiam essas condições. Neste caso, o contexto imediato é o lugar onde o cartaz foi produzido e colocado, os sujeitos que o assinaram e permitiram a sua divulgação e toda a conjuntura que envolve a organização em si. Sob um olhar das Relações Públicas, essas posições-sujeito, no âmbito organizacional, estão inseridas no maior nível hierárquico, uma vez que podem reproduzir informações por meio de mídias que auxiliam, de alguma forma, a produção da organização.

Os outros contextos são mais amplos e envolvem diversos fatores de interesse para a análise: o contexto social é o que estrutura a instituição tal como ela é, o modo como o nível hierárquico e os poderes se articulam e os outros elementos que estão presentes no sistema e relacionam-se com a organização; o ideológico, por sua vez, traz ideologias que a organização pretende propagar ou apenas propaga aos seus públicos por meio de seus discursos; o histórico envolve os acontecimentos que, de alguma forma, promoveram a constituição desse discurso, como, por exemplo, outros cartazes de outras organizações, informações veiculadas na mídia sobre o tema e a construção do senso comum sobre o vírus HIV.

Ao analisar o cartaz, em um primeiro momento, precisamos entender as formações imaginárias, tal como são definidas por Pêcheux (1990), ou seja, 
compreender a imagem que os sujeitos desse processo discursivo fazem da posição discursiva de si e do outro. Consideramos em A o interlocutor organização, que, após todo o processo de produção do texto, dirige-se aos colaboradores, a fim de informá-los sobre o vírus que possibilita o desenvolvimento da Aids nas pessoas contaminadas. A empresa, avaliando a sua conjuntura organizacional, conscientiza por meio de textos e mídias, pois tem o poder de informar e conscientizar nessa estrutura e no relacionamento que constrói com seus funcionários, responsabilizando-se pelos textos publicados e pelos efeitos de sentidos que podem surgir a partir dos discursos promovidos.

$\mathrm{Na}$ outra posição discursiva, em B, temos os colaboradores da instituição, em outros termos, o público interno: para quem o texto foi produzido e se tinha o intuito de conscientizar. Por mais que não se tenha nenhum direcionamento marcado por algum vocativo, entendemos que o cartaz se endereça a esse público pelo fato de estar colocado no ambiente interno da organização, onde os colaboradores circulam, e por ter um conteúdo que visa a sensibilizar as pessoas em relação a uma causa de política pública (o vírus HIV, neste caso).

Dessa maneira, a partir das afirmações de Orlandi (2007), entendemos que o que possibilita a interlocução entre a empresa e os seus funcionários sobre o combate ao vírus HIV nesse discurso é a relação de forças que se estabelece entre os interlocutores: de um lado, o interlocutor $A$, ao utilizar a expressão não faça sexo,chama a atenção do interlocutor $B$, a fim de direcioná-lo a um comportamento específico.

Uma vez atingido o objetivo dessa ação, a resposta do interlocutor $B$, sem o mesmo direito à voz, seria não fazer sexo com as pessoas da cidade Santa Cruz do Sul. Além disso, é interessante pensarmos, pelo viés da comunicação, que a iniciativa dessa empresa dá-se pelo fato de que as organizações brasileiras, para que sejam socialmente vistas como instituições que estão atentas às problemáticas que cercam os seus públicos e o ambiente em que estão inseridas, estabelecem políticas de responsabilidade social que visam à conscientização sobre determinado tema (CAMPOS, 2004).

Também, podemos argumentar sobre a imagem que a organização tem de seus colaboradores, ou seja, a imagem que A tem sobre B para que the fale assim, a partir da injunção não faça: esses colaboradores devem ser orientados e, consequentemente, aderir ao discurso da instituição. No texto, existe um limite geográfico em relação às pessoas com as quais não se 
deve fazer sexo: com pessoas de Santa Cruz do Sul. Isso pode nos dizer que a organização acredita que os funcionários mantêm relações sexuais com as pessoas de Santa Cruz do Sul, e não com as pessoas que habitam as outras cidades da região onde a instituição está localizada.

Além das posições dos sujeitos, devemos trazer o sentido histórico presente no texto. Entendemos, então, a importância da memória discursiva para a produção desse discurso. A memória, considerada como interdiscurso, de acordo com Orlandi (2007), é um elemento que auxilia na execução do discurso, pois todos os discursos são atravessados por outros e se constituem por meio dos outros. A produção desse cartaz se dá a partir do que se sabe sobre o assunto: e o que se sabe já foi dito em outros textos como, por exemplo, em uma mídia de massa que noticia e constrói uma narrativa sobre o que é o vírus HIV e quais são os problemas que dele decorrem.

Analisando o enunciado verbal em destaque, entendemos que essa campanha procura promover o combate a esse vírus. Mas, de onde vem essa informação de que o vírus HIV é transmitido pelo ato sexual, uma vez que está escrito "não faça sexo"? Essa informação vem do conhecimento de outros discursos (notadamente, do âmbito das ciências da saúde) sobre uma das formas de contágio, que foram sendo construídos por textos científicos e pelo senso comum (com o auxílio do discurso de divulgação científica) a partir da historicidade.

Os fundamentos sobre historicidade também promovem um olhar diferenciado para o discurso materializado no cartaz, por meio dos sentidos que as cores dispostas nesse instrumento de comunicação podem produzir, já que as significações socioculturais das cores são construídas no decorrer dos acontecimentos históricos de determinadas sociedades/comunidades. Nesse enunciado, vemos o destaque da cor vermelha, que pode potencializar, na conjuntura onde a organização está inserida, inúmeros efeitos, dentre os quais uma advertência, uma possível proibição, reforçada pelo elemento verbal, e, inclusive, o sangue: tecido líquido do corpo humano e um dos meios de transmissão do vírus HIV.

A partir dessas considerações sobre o cartaz e sobre sua repercussão na mídia, entendemos que o texto causou efeitos de sentido que podem levar à conclusão de que todas as pessoas de Santa Cruz do Sul possuem HIV, dados pela generalização que pode ser lida na sequência linguística; sentidos estes que podem ser contestados. Não há delimitação no texto. De acordo 
com Pereira e Silva (2015, p. 333), "sabe-se que qualquer pessoa pode colocar-se em risco se mantiver relações sexuais com vários parceiros [..]”, o que nos leva a pensar que, independentemente da cidade ou região, basta manter relações sexuais desprotegidas para que se esteja vulnerável ao vírus. Assim, podemos compreender que o discurso reproduz alguns preconceitos com os moradores do município, devido aos índices de contaminação pelo vírus HIV, e com as pessoas soropositivas.

A informação sobre o número de contaminados pelo vírus na cidade está presente no cartaz, com referência a quem contabilizou esses dados logo abaixo das palavras que ganharam mais destaque. Cerca de 950 pessoas são portadoras confirmadas do vírus que desenvolve a doença Aids, porém, há uma estimativa de que mais de 2500 pessoas já estejam contaminadas. A partir dos dados obtidos no censo do IBGE 2016, a população de Santa Cruz do Sul é de 126.775. Esses dados reforçam o caráter de generalização no texto principal da campanha de conscientização social, pois os índices de pessoas contaminadas pelo vírus não representam nem $1 \%$ da população total do município.

Além disso, é necessário observarmos os enunciados que encerram o cartaz: "se por acaso você não conhece todas estas pessoas, retire aqui a única forma segura de se prevenir". No primeiro enunciado, observamos o texto organizado paradoxalmente, já que sabemos, por meio do senso comum, que dificilmente conhecemos todas as pessoas de um determinado local, ainda mais um grupo com as mesmas características específicas, nesse caso com a contaminação por determinado vírus. Nesse mesmo enunciado, podemos notar a estratégia de comunicação para tentar convencer o público a retirar o preservativo, quando o próprio texto utiliza termos para deixar a ideia de que é impossível aos funcionários conhecer as 950 pessoas contaminadas ou as 2500 suspeitas.

Em seguida, no segundo enunciado, as afirmações do texto do cartaz dizem que a única maneira de se prevenir contra o vírus HIV é por meio da camisinha, pois, por mais que as palavras preservativo e/ou camisinha não estejam escritas, pode-se observar que "a única forma segura de se prevenir" está se referindo ao envoltório plástico, colado ao cartaz abaixo das últimas palavras, que disponibiliza preservativos para o público-alvo da campanha. Porém, a campanha funda-se sobre uma contradição, visto que, ao mesmo tempo em que sugere o uso do preservativo, difunde a ideia de que não se pode fazer sexo com quem é soropositivo, sugerindo que a camisi- 
nha não tem a capacidade de proteger.

Outro ponto a ser mencionado no cartaz é o que não está escrito, pois, de acordo com Orlandi (2007), no não-dito há uma relação de sentidos com o que foi dito: o não-dizer relaciona-se às noções de interdiscurso, de ideologia e de formação discursiva, visto que se prefere dizer "x" e não " $y$ ". $E$, a partir do momento que uma palavra é escolhida para fazer parte do enunciado, outras palavras são silenciadas, o que caracteriza o processo de silêncio constitutivo (ORLANDI, 2007): se falo "não faça sexo com pessoas de Santa Cruz do Sul" não falo "previna-se do vírus HIV em Santa Cruz do Sul". Nessa perspectiva, o que subjaz ao discurso pode produzir determinados sentidos, a partir do que foi escolhido (não) dizer. Nesse caso:

a) O cidadão e cidadã de Santa Cruz do Sul são soropositivos.

b) As 950 pessoas detectadas com a doença representam toda a população da cidade.

c) Não se pode fazer sexo com pessoas portadoras do vírus HIV.

d) O preservativo não protege.

Logo, é importante observamos as problemáticas que podem ser desenvolvidas por meio da circulação desse discurso, visto que pode representar os soropositivos de maneira equivocada, gerando preconceitos e discriminação para com esse grupo no âmbito social, caso o cartaz tenha caráter influenciador.

Também, com base nesse leque de possibilidades de sentidos que o discurso materializado no cartaz da campanha em combate ao vírus HIV pode produzir, entende-se que todos os habitantes estão sendo retratados como portadores do vírus. Por mais que exista a informação do número de pessoas contaminas ou possíveis contaminadas, nota-se que esse enunciado pode promover a ideia de que 950 pessoas representam os 126 mil habitantes do município nesse contexto.

\section{CONSIDERAÇÕES FINAIS}

Após o aprofundamento teórico, partindo do ponto de vista dos autores referidos neste estudo, entendemos que o discurso é efeito de linguagem, materializando-se na língua, nas falas e nos textos, e constituído por meio das condições de produção, que não se limitam somente aos mecanismos linguísticos:os aspectos históricos, sociais e ideológicos dos sujeitos discursivos devem ser considerados para o desenvolvimento da análise e para a compreensão dos diferentes sentidos que podem ser produzidos por um 
mesmo enunciado.

Considera-se, sob esse ponto de vista, que o discurso materializado no cartaz da campanha idealizada pela empresa, localizada na cidade de Santa Cruz do Sul, pode ser visto como inapropriado e discriminatório na sua circulação, pois produz efeitos de sentido que permitem o entendimento de que todos os habitantes do município estão contaminados e sugere que as pessoas não transem com quem é soropositivo. Além do preconceito que pode ser gerado com os portadores do vírus, o cartaz é paradoxal, pois não só pede o uso do preservativo, como também pede para que o sexo não seja feito, produzindo o sentido de que a preservativo não protege nos atos sexuais.

No que concerne às condições de produção e circulação, o objeto analisado permite refletir sobre o papel das mídias de massa e da ambiência midiatizadaz na disseminação dos discursos e na produção de seus sentidos, uma vez que possuem grande alcance perante os diversos públicos com que as organizações se relacionam e promovem determinadas imagens a partir das distintas leituras que estes podem realizar.

2 De acordo com os fundamentos teóricos de Barichello (2014), a midiatização é um termo que se utiliza na área de comunicação para explicar o processo de influência dos meios de comunicação na sociedade. O conceito engloba mídia, cultura e a ambiência social, considerando a mídia como a matriz das relações sociais, uma vez que é entendida como um sistema que expande as interações nos ambientes virtuais e modifica a maneira de compreender e organizar o real. 


\section{REFERÊNCIAS}

BARICHELLO, Eugenia Maria Mariano da Rocha. Midiatização e cultura nas organizações da contemporaneidade: o processo de midiatização como matriz de práticas sociais. In: MARCHIORI, Marlene (Org.). Contexto Organizacional Midiatizado. São Paulo; Rio de Janeiro: Difusão; Senac, 2014, v. 8, p. 37-43.

BARONAS, Roberto Leiser. Efeito de sentido de pertencimento à análise do discurso. Anais do II SEAD - Seminário de Estudos do Discurso, 2005, Porto Alegre/RS. Disponível em: <http://www.ufrgs.br/analisedodiscurso/anaisdosead/2SEAD/SIMPOSIOS/RobertoLeiserBaronas.pdf >. Acesso em: 06 dez. 2016.

BRASIL, Leão Luciana. Michel Pêcheux e a teoria da Análise de Discurso: desdobramentos importantes para a compreensão de uma tipologia discursiva. Linguagem - Estudos e Pesquisas. Vol. 15, n. 01, p. 171-182, 2009. Disponível em: < https://www.revistas.ufg.br/ lep/article/viewFile/32465/17293. Acesso em: 06 dez às 11h18min. 2016.

CAMPOS, Tatiana Moreira. Responsabilidade social e comunicação organizacional estratégica. Monografia FACOM, UFJF, $2^{\circ}$ sem 2004.Disponível em: <http://www.ufff.br/ facom/files/2013/04/TCampos.pdf. Acesso em: 06 jun. às 14h27min. 2017.

FERNANDES, C. A. Análise do discurso: Reflexões introdutórias. São Carlos: Editora Claraluz, 2008.

GADET, Francoise; HAK, Tony (Orgs.). Por uma analise automática do discurso: uma introdução à obra de Michel Pêcheux. Campinas, SP: Editora da UNICAMP, 1990.

KUNSCH, Margarida. Planejamento de relações públicas na comunicação integrada. Guarulhos: Summus Editorial, 2003.

G1. Cartaz pede que ninguém faça sexo com moradores de cidade do RS. Disponível em: <http://g1.globo.com/rs/rio-grande-do-sul/noticia/2015/05/cartaz-pede-que-ninguem-faca-sexo-com-moradores-de-cidade-do-rs.html. Acesso em: 28 nov às 9h. 2016.

ORLANDI, Eni P. Análise do discurso: princípios e procedimentos. 7. ed. Campinas: Pontes, 2007.

ORLANDI, Eni P. Discurso, imaginário social e conhecimento. Em aberto, v. 14, n. 61, p. 52-59, 1994.Disponível em: http://emaberto.inep.gov.br/index.php/emaberto/article/ view/1943/1912 Acesso em:09 nov às 17h. 2017.

Portal do Departamento de IST, Aids e Hepatites Virais. Disponível em: <http://www.aids. gov.br/pagina/o-que-e-hiv. Acesso em 05 dez às 22h10min. 2016.

SANTAELLA, Lucia. Dos não-lugares à cidade senciente. Revista do laboratório dos estudos urbanos do núcleo de desenvolvimento da criatividade. 2014. Disponível em: < http://periodicos.sbu.unicamp.br/ojs/index.php/rua/article/view/8638917/6520. Acesso em: 28 nov. 2016.

Site IBGE. Disponível em: <http://cidades.ibge.gov.br/xtras/perfil.php?codmun=431680. Acesso em: 06 dez às 16h2omin. 2016.

ZH. Campanha que diz não faça sexo com pessoas de Santa Cruz do Sul gera polêmica. 
Disponível em: <http://zh.clicrbs.com.br/rs/noticias/noticia/2015/05/campanha-que-diz-nao-faca-sexo-com-pessoas-de-santa-cruz-do-sul-gera-polemica-4755802.html. Acesso em: 23 jun às gh3omin. 2017.

ZH. RS é o Estado com maior índice de casos de Aids por habitante aponta Ministério. Disponível em: <http://zh.clicrbs.com.br/rs/vida-e-estilo/noticia/2011/11/rs-e-o-estado-com-maior-indice-de-casos-de-aids-por-habitante-aponta-ministerio-3577270.html. Acesso em: 29 nov às 10h. 2016. 


\section{Paulo Eduardo Dóro Prestes}

É graduando em Relações Públicas na Universidade Federal de Santa Maria, campus Frederico Westphalen. Participou do grupo de pesquisa COTECS - Comunicação, Tecnologia e Sociabilidades, realizou estágios na Agência KS e VirtualBit e foi bolsista de iniciação científica (FAPERGS) no projeto de pesquisa Discurso, Poder e Políticas da (In)visibilidade.

E-mail: eduard2298@gmail.com

\section{Marluza da Rosa}

Professora-Adjunta do Departamento de Ciências da Comunicação da Universidade Federal de Santa Maria, Campus Frederico Westphalen (UFSM/FW). Graduada e Mestre em Letras pela Universidade Federal de Santa Maria e Doutora em Linguística Aplicada pela Universidade Estadual de Campinas. Suas pesquisas abordam a leitura, a escrit(ur)a e a subjetividade nos/dos discursos universitário-científico e midiático.

E-mail: marluza.rosa@gmail.com 